\section{Considerations about exhibition design after the creation of an audiovisual display for the exhibition Paul Klee - Unstable Balance}

\section{Daniel Grizante}

Universidade Anhembi Morumbi

In 2019, I was with the design team of the exhibition Paul Klee - Equilíbrio Instável, held in the various spaces of the Banco do Brasil Cultural Center, in the cities of São Paulo, Rio de Janeiro and Belo Horizonte. It was an exclusive exhibition for Brazil that brought together 120 works by the artist, from the collection of Zentrum Paul Klee from Bern, Switzerland. At that time, I made an audiovisual display on five screens, which presented to the visitors aspects of the artistic techniques developed and used by the artist in his vast work.

This research is part of a broader one, on the use of audiovisual in expographic projects that is the subject of my doctoral thesis, in progress. At this moment, however, a reflection will be presented on this specific audiovisual display, held for the exhibition cited. Our goal was to look at the various tensions that apply to the process of construction of a piece of this type, from the point of view of the design project. As well as the search for the function performed by it within the exhibition project.

To do this reflection we started with a contextualization of this modality of exhibition using as object of study its edition held at the Banco do Brasil Cultural Center of São Paulo (CCBB-SP), looking at the spaces and their exhibition issues and its influence on the development of the project. We present, in the sequence, a description of the exhibition as a whole from the visitor point of view and from its catalog. Production files from this audiovisual display were researched, such as first drawings, scripts, concept development archives, photographic material and versions developed until its final. This material was observed from the concept of the creation networks, by Cecília Almeida Salles. We also held a dialogue with other
Orcid number 0000-0002-7776-1671 members of the creative team, from different levels of the production process, in order to know the tensions that are applied in the production of this limited element of an expographic project like this.

We saw, in this specific case of producing an audiovisual display, how each constituent element of an exhibition like this is traversed by tensions of various types, which are common within an exhibition design project, with many professionals from different areas involved. In addition to the identification of external factors that directly influence its production.

We conclude then that the development of an exhibition is now inserted within what we know as a culture of design, which allows us to look at this type of cultural manifestation as something that can no longer be limited to previous models of idealization of the exhibition space or abstain from the use of technologies and possibilities of connection with the public.
KEYWORDS

Exhibition design, Audiovisual display, Exhibition, Paul Klee, Design culture 